\title{
Decompressive craniectomy in herpes simplex encephalitis
}

\author{
Muhammed Jasim Abdul Jalal ${ }^{1}$, Shirley Joan Fernandez², Prithvi Varghese ${ }^{3}$, Murali Krishna Menon ${ }^{2}$ \\ ${ }^{1}$ Department of Family Medicine, Lakeshore Hospital and Research Centre, Kochii 682040, Kerala, India. \\ ${ }^{2}$ Department of Neurology, Lakeshore Hospital and Research Centre, Kochii 682040, Kerala, India. \\ ${ }^{3}$ Department of Neurosurgery, Lakeshore Hospital and Research Centre, Kochii 682040, Kerala, India.
}

\section{A B S T R A C T}

Intracranial hypertension is a common cause of morbidity in herpes simplex encephalitis (HSE). HSE is the most common form of acute viral encephalitis. Hereby we report a case of HSE in which decompressive craniectomy was performed to treat refractory intracranial hypertension. A 32-year-old male presented with headache, vomiting, fever, and focal seizures involving the right upper limb. Cerebrospinal fluid-meningoencephalitic profile was positive for herpes simplex. Magnetic resonance image of the brain showed swollen and edematous right temporal lobe with increased signal in gray matter and subcortical white matter with loss of gray, white differentiation in T2-weighted sequences. Decompressive craniectomy was performed in view of refractory intracranial hypertension. Decompressive surgery for HSE with refractory hypertension can positively affect patient survival, with good outcomes in terms of cognitive functions.

Key words: Decompressive craniectomy, herpes simplex encephalitis, refractory intracranial hypertension

\section{INTRODUCTION}

Herpes simplex encephalitis (HSE) is the most common form of acute viral encephalitis. ${ }^{[1]}$ HSE is caused by herpes simplex virus types 1 and 2 (HSV-1 and HSV-2), two DNA viruses of the Herpesviridae family. HSV is the most frequent agent of sporadic fatal encephalitis with an annual incidence of 1 in 250,000-500,000. ${ }^{[2]}$ Untreated HSE has an extremely high mortality rate of 70\%. ${ }^{[3]}$ Early diagnosis and treatment can reduce the mortality rate to $19 \% \cdot .^{[4,5]}$ Morbidity in HSE is mainly due to intracranial hypertension. ${ }^{[4]}$ Therefore, we report a rare case of HSE, which required decompressive craniectomy to treat severe refractory intracranial hypertension.

Patients with HSE usually present with headache, confusion, fever, and seizures. ${ }^{[6]}$ Failure to diagnose this serious disease early may result in permanent disability or death. The presence of clinical symptoms

\begin{tabular}{|l|l|}
\hline \multicolumn{2}{|c|}{ Access this article online } \\
\hline Quick Response Code: & \\
\hline & Website: \\
\hline & www.nnjournal.net \\
\hline
\end{tabular}

and a localized lesion in the temporal lobe usually reflects HSE, but other diseases can also mimic this condition. ${ }^{[7]}$ Cerebrospinal fluid (CSF) examination is indicated for suspected HSE patients even if the intracranial pressure is increased. ${ }^{[7]}$

Herpes simplex virus usually causes a mild disease restricted to the skin and mucosa. Much less commonly, it causes severe encephalitis. While HSV-1 is typically transmitted via the oro-labial route, HSV-2 is transmitted venereally. HSV-1 strains are etiological agents in over $90 \%$ of cases of HSE. HSV-2 strains are more commonly isolated in congenitally acquired neonatal HSV meningoencephalitis. After initial replication in skin and mucosa, the HSV-1 virus infects the sensory nerve endings innervating the infected territory and migrates along retrograde axonal flow toward the trigeminal ganglia where it remains latent.

The mechanisms whereby HSV-1 penetrates the nervous system, evades the immune response and causes encephalitis are incompletely understood. HSV could enter into the brain by reactivation of the viral genome in the trigeminal ganglion with axonal spread via the trigeminal nerve into the temporal and frontal lobes. Furthermore, HSV-1 can primarily infect the central nervous system.

Corresponding Author: Dr. Muhammed Jasim Abdul Jalal, Department of Family Medicine, Lakeshore Hospital and Research Centre, NH-47 Bypass, Maradu, Nettoor, Kochii 682040, Kerala, India. E-mail: poolspuff@gmail.com 


\section{CASE REPORT}

A 32-year-old male presented with headache, vomiting, fever, and focal seizures involving the right upper limb of 1-week duration. There was no significant past history. There was no history suggestive of any immunodeficiency. On examination, the patient was hemodynamically stable and conscious but febrile and irritable. He had no focal neurological deficits but had signs of meningeal irritation. The pupils were equal in size and reactive. Magnetic resonance imaging of brain (MRI-brain) [Figure 1] showed swollen and edematous right temporal lobe (a) with increased signal in gray matter and subcortical white matter with loss of gray white differentiation in T2-weighted sequences. There was a signal change in the right insula and sub frontal cortex bilaterally. Restricted diffusion and abnormal leptomeningeal enhancement were also noted. There was mass effect with partial effacement of the body of the right lateral ventricle and midline shift (b). A guarded lumbar puncture was done and CSF study [Table 1] showed protein: $60 \mathrm{mg} / \mathrm{dL}$, sugar: $87 \mathrm{mg} / \mathrm{dL}$, and 200 cells $/ \mathrm{mm}^{3}$ with lymphocytic pleocytosis. CSF meningoencephalitic profile was positive for herpes simplex 1 virus.

Cerebrospinal fluid meningoencephalitis profile [Table 1] is a polymerase chain reaction (PCR) equivalent. This is a molecular diagnostic screening technology involving isolation of the genetic material of the causative agent from the given specimen and

\begin{tabular}{ll}
\hline Table I: CSF study & \\
\hline Parameters & Results \\
\hline CSF protein & $60 \mathrm{mg} / \mathrm{dL}$ \\
CSF sugar & $87 \mathrm{mg} / \mathrm{dL}$ \\
CSF cells & $200 \mathrm{cells} / \mathrm{mm}^{3}$ with predominantly \\
& polymorphs (P64, L28) \\
CSF meningo- & Positive for herpes simplex-1 \\
encephalitic profile & \\
\hline CSF: cerebrospinal fluid &
\end{tabular}

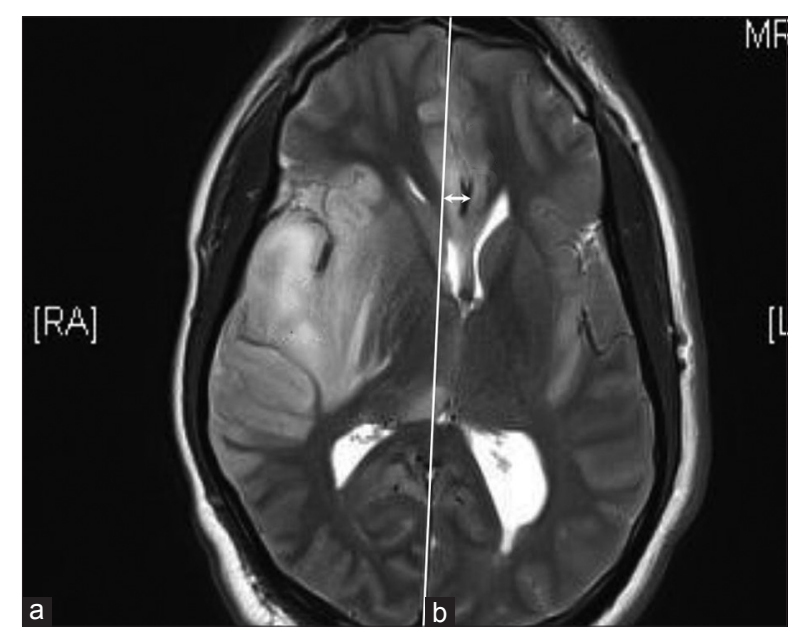

Figure 1: Magnetic resonance imaging of brain: T2-weighted sequence showing swollen and edematous right temporal lobe (a) with mass effect (b) and midline shift as indicated by the arrow simultaneous amplification of the "syndrome specific signature genes" of all the probable causative agents, followed by "syndrome specific hybridization".

Based on a presumptive diagnosis of HSE, the patient was started on intravenous acyclovir (500 mg 8th hourly). He was also started on anti-cerebral edema medications, intravenous 20\% mannitol $150 \mathrm{~mL}$ 6th hourly, and steroids (dexamethasone) $8 \mathrm{mg}$ 8th hourly. His sensorium deteriorated soon after admission, being unresponsive (Glasgow coma scale: 5/15) (eye response 1 , verbal response 1 , motor response 3 ) and the right pupil dilated. The patient was emergently intubated and connected to ventilator. Since the patient was already on full-fledged anti-cerebral edema medications, surgical options were then considered as the second measure. A decompressive surgery was immediately performed by a large right frontotemporoparietal craniectomy. The dura was widely opened and lesional tissue of the right temporal was harvested for biopsy. No parenchymal resection was necessary since the brain was adequately decompressed. Dura was closed with an expansive duroplasty. The bone flap was not replaced; instead was preserved in the anterior abdominal wall. Anti-cerebral edema medications were tapered and stopped postoperatively.

Postoperatively, his neurological status stabilized and was weaned off ventilator gradually. Postoperative computed tomography (CT) of brain [Figure 2] after 3 days showed resolution of the mass effect with no midline shift. However, the right temporal lobe remained hypodense. Basal ganglia, thalamus, internal capsule, and caudate nucleus appeared normal.

Electroencephalography (EEG) in the postoperative period showed diffuse right hemispherical slowing in theta to delta range [Figure 3]. Histopathology of the right temporal lesion [Table 2] revealed infiltration

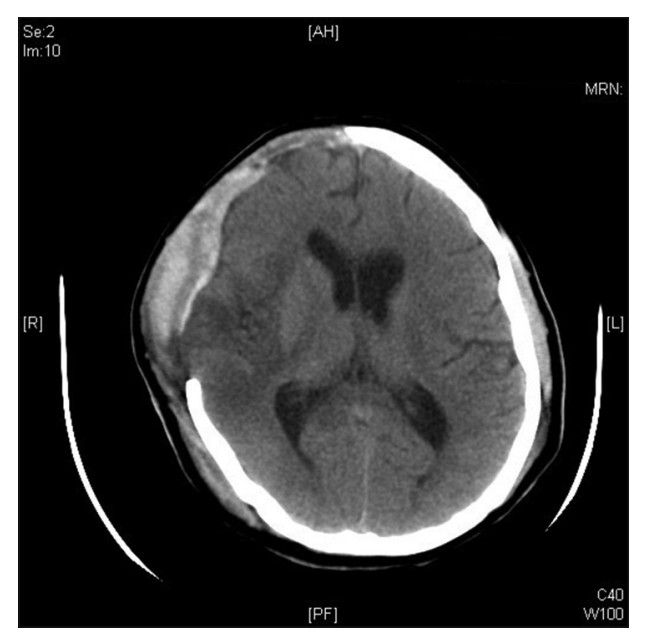

Figure 2: Postoperative computed tomography of brain after 3 days showing resolution of the mass effect with no midline shift 
by inflammatory cells and perivascular lymphocytic cuffing [Figure 4] with occasional multinucleated giant cells, consistent with the well-known pathology of HSE. The patient was discharged on the 10th postoperative day in a recovering condition.

Over the next few months, the patient made a remarkable neurological recovery. He regained full consciousness and normal cognition. He did not have further episodes of seizures. He has no residual neurological deficits. Two months after the craniectomy, the bone flap was replaced.

\section{DISCUSSION}

In HSE, delay in treatment leads to severe neurological sequelae. Therefore, early diagnosis is of great importance. Diagnostic criteria include clinical symptoms, MRI, EEG, and CSF studies [Table 3]. The sensitivity is increased with the combination of these neurodiagnostic tests. ${ }^{[12]}$ When HSE is suspected, MRI brain should be done as early as possible as signs of HSE could be detected by MRI earlier than CT scan. ${ }^{[13]}$ Because MRI is a more sensitive and specific diagnostic tool, it is used instead of CT scans in the majority of patients. ${ }^{[13-15]}$ The characteristic MRI finding of HSE is hyperintense areas (T2-weighted sequences) in the inferior part of temporal lobes, medial part, and insula. This may also be observed in the frontal and parietal lobes. Bilateral temporal lobe involvement has been reported to be pathognomonic of HSE. ${ }^{[16]}$ Diffusion limitation observed in T2-FLAIR sequences are also thought to be typical. ${ }^{[16]}$

Herpes simplex encephalitis is a medical emergency that requires prompt diagnosis and therapy. However, both are often delayed for several reasons. For instance, the clinical presentation itself is non-specific and may be mistaken for stroke, epilepsy, delirium or a primary psychiatric disorder. CSF cell count is normal in 5-10\%

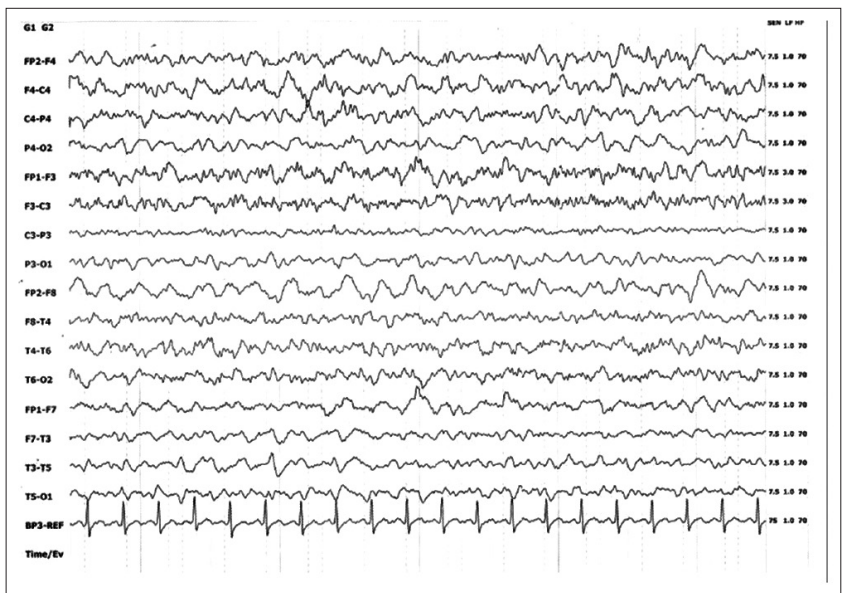

Figure 3: Electroencephalography showing diffuse right hemispherical slowing in theta to delta range of patients. Neuroimaging may be normal in the early stages. DNA detection may be negative. ${ }^{[17]}$

Untreated HSE is progressive and often fatal in 7-14 days. A landmark study by Whitley et al. ${ }^{[18]}$ in 1977 revealed a $70 \%$ mortality in untreated patients and severe neurologic deficits in most of the survivors. Mortality in patients treated with acyclovir was $19 \%$ in the trials that established its superiority to vidarabine. Subsequent trials reported lower mortalities (6-11\%), perhaps because they included patients who were diagnosed by PCR rather than brain biopsy and who

\begin{tabular}{|c|c|}
\hline Parameters & Results \\
\hline Microscopy & $\begin{array}{l}\text { Sections show pieces of cerebral cortex and } \\
\text { subcortical white matter in which there is edema, } \\
\text { focal hemorrhage and infarction with infiltration by } \\
\text { inflammatory cells } \\
\text { Perivascular lymphocytic cuffing and occasional } \\
\text { multinucleated giant cells noted } \\
\text { No viral inclusions/granuloma seen } \\
\text { There is no evidence of malignancy }\end{array}$ \\
\hline Diagnosis & $\begin{array}{l}\text { Brain biopsy: consistent with herpes simplex } \\
\text { encephalitis }\end{array}$ \\
\hline
\end{tabular}

Table 3: Diagnostic criteria for HSE. HSE is diagnosed in a febrile patient with an altered level of consciousness *in the presence of any 3 of the following diagnostic tests

\section{Criteria}

EEG showing background slowing and frequent PLEDs over the temporal lobe ${ }^{[8]}$

MRI-Brain showing gyral edema in T1-weighted sequences and high signal intensities over the medial temporal lobe and the cingulate gyrus in T2, FLAIR and diffusion-weighted sequences, often with foci of hemorrhage $e^{[0]}$

CSF showing lymphocytic pleocytosis, elevated protein and elevated CSF opening pressure ${ }^{[10]}$

Detection of herpes simplex virus DNA in the CSF by polymerase chain reaction: gold standard for diagnosis ${ }^{[1]]}$

*With or without focal neurological deficits. EEG: electroencephalography; PLEDs: periodic lateralized epileptiform discharges; MRI-Brain: magnetic resonance imaging of brain;CSF: cerebrospinalfluid; HSE: herpes simplexencephalitis; FLAIR:fluidattenuated inversion recovery; DNA: deoxyribonucleic acid

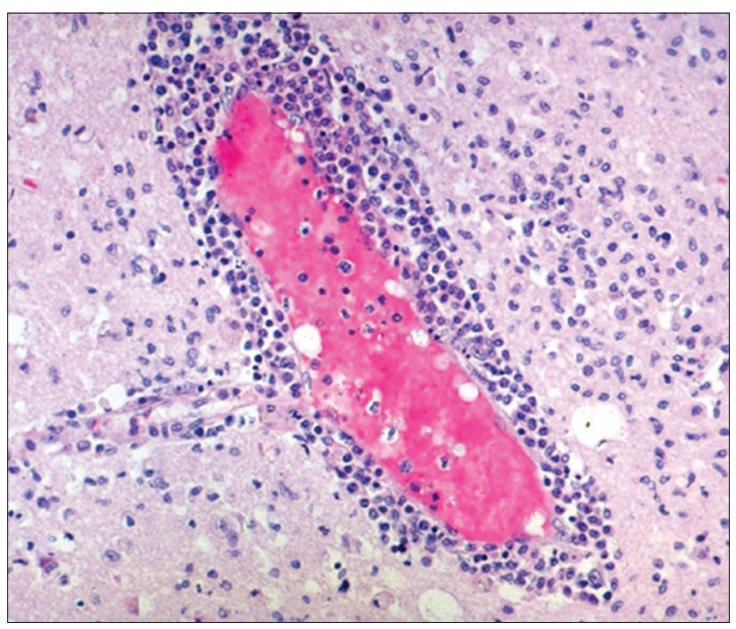

Figure 4: Histopathology of the right temporal lesion showing infiltration by inflammatory cells and perivascular lymphocytic cuffing, which is consistent with herpes simplex encephalitis 


\begin{tabular}{|c|c|c|}
\hline \multicolumn{3}{|c|}{ Table 4: Diagnosis of HSE in the present case } \\
\hline Diagnostic tests & Characteristic findings & Present case \\
\hline $\mathrm{EEG}^{[8]}$ & $\begin{array}{l}\text { Background slowing and frequent PLEDs over the temporal lobe } \\
\text { Usually, present from day } 2 \text { to day } 14 \text { after disease onset }\end{array}$ & $\begin{array}{l}\text { Showed diffuse right hemispherical } \\
\text { slowing in theta to delta range }\end{array}$ \\
\hline Neuroimaging ${ }^{[9]}$ & $\begin{array}{l}\text { MRI is more sensitive and specific than CT } \\
\text { Early findings include gyral edema in T1-weighted sequences } \\
\text { and high signal intensities over the medial temporal lobe and the } \\
\text { cingulate gyrus in T2, FLAIR and diffusion-weighted sequences, } \\
\text { often with foci of hemorrhage } \\
\text { Bilateral assymetrical temporal lobe and cingulate gyrus involvement } \\
\text { is nearly pathognomonic of HSE but is a late development }\end{array}$ & $\begin{array}{l}\text { T2-weighted sequence showed swollen } \\
\text { and edematous right temporal lobe. } \\
\text { Restricted diffusion and abnormal } \\
\text { leptomeningeal enhancement were also } \\
\text { noted }\end{array}$ \\
\hline CSF study ${ }^{[10]}$ & $\begin{array}{l}\text { Elevated CSF opening pressure } \\
\text { Lymphocytic CSF pleocytosis } \\
\text { Elevated proteins } \\
\text { Normal glucose }\end{array}$ & $\begin{array}{l}\text { CSF protein: } 60 \mathrm{mg} / \mathrm{dL} \\
\text { CSF sugar: } 87 \mathrm{mg} / \mathrm{dL} \\
\text { CSF cells: } 200 \mathrm{cells} / \mathrm{mm}^{3} \text { with } \\
\text { predominantly lymphocytes (P28, L64) }\end{array}$ \\
\hline $\begin{array}{l}\text { Virological } \\
\text { diagnosis }^{11]}\end{array}$ & $\begin{array}{l}\text { Gold standard for diagnosis } \\
\text { Detection of herpes simplex virus DNA in the CSF by PCR }\end{array}$ & $\begin{array}{l}\text { CSF meningoencephalitis profile: positive } \\
\text { for herpes simplex-1 }\end{array}$ \\
\hline Brain biopsy ${ }^{[27,28]}$ & $\begin{array}{l}\text { Microscopically, necrosis is associated with diffuse inflammation and } \\
\text { perivascular lymphocytic infiltration. Viral intranuclear inclusions are } \\
\text { inconstant, and viral antigens are detectable only at early stages }\end{array}$ & $\begin{array}{l}\text { Inflammatory cell infiltration and } \\
\text { perivascular lymphocytic cuffing consistent } \\
\text { with HSE. No herpes inclusions were seen }\end{array}$ \\
\hline
\end{tabular}

HSE: herpes simplex encephalitis; EEG: electroencephalography; PLEDs: periodic lateralized epileptiform discharges; MRI: magnetic resonance imaging; CT: computed tomography; CSF: cerebrospinal fluid; PCR: polymerase chain reaction; FLAIR: fluid-attenuated inversion recovery; DNA: deoxyribonucleic acid

thus may have been identified earlier with milder cases of HSE. ${ }^{[19]}$

Sequelae among survivors are significant and depend on the patient's age and neurologic status at the time of diagnosis. Patients who are comatose at diagnosis have a poor prognosis regardless of their age. In non-comatose patients, the prognosis is age related, with better outcomes occurring in patients younger than 30 years. Anterograde memory often is impaired even with successful treatment of HSE. Retrograde memory, executive function, and language ability may also be impaired. A study by Utley et al. ${ }^{[20]}$ showed that patients who had a shorter delay ( $<5$ days) between presentation and treatment had better cognitive outcomes. Furthermore, Marschitz et al. ${ }^{[21]}$ reported a case of chorea after HSE.

Despite adequate medical treatment, some HSE patients worsen because of refractory intracranial hypertension. A decompressive craniectomy (in which the skull flap is not immediately replaced, allowing the brain to swell, thus reducing intracranial pressure), with or without anterior temporal lobe resection, can be effective in controlling intractable, elevated intracranial pressure in HSE. ${ }^{[22,23]}$

Taferner et al. ${ }^{[24]}$ reported the long-term sequelae (1.5-8 years after craniectomy) of four cases with HSE and confirmed its appropriateness, as it led to full cognitive recovery, resocialization, and reintegration into professional life. Ebel et al. ${ }^{[25]}$ suggested that not only a decompressive craniectomy, but also a partial resection of the temporal lobe may be of benefit for patients with tentorial herniation, because both decompression and reduction of infectious material with cystic tissue necrosis can be achieved. Moreover, the initial neurologic deficit does not affect the long-term clinical outcome if decompression is done in the early stages. ${ }^{[26]}$

In conclusion, we were able to diagnose HSE with the help of clinical findings, MRI-brain, analysis of CSF profile showing lymphocytic pleocytosis and detection of HSV DNA, in our patient [Table 4]. EEG showed diffuse right hemispherical slowing in theta to delta range and brain biopsy was consistent with HSE. Initially, the patient was initiated on empirical acyclovir therapy and anti-cerebral edema medications but later on decompressive craniectomy was necessary to treat refractory intracranial hypertension. Following surgery the patient showed remarkable neurological recovery. Hence, we conclude that, for patients with HSE, it is important for the clinician to detect deterioration of consciousness because of the mass effect caused by the disease-associated inflammatory process as early as possible. Timely recognition of refractory intracranial hypertension and surgical decompression in HSE can be life-saving. Increased intracranial pressure during HSE may be so grave that it may cause a shift of intra-cerebral structures, thus increasing the morbidity and mortality. Decompressive surgery for HSE with refractory hypertension can positively affect patient survival, with good outcomes in terms of neurological recovery.

\section{REFERENCES}

1. Whitley R, Kimberlin DW, Roizman B. Herpes simplex viruses. Clin Infect Dis 1998;26:541-53.

2. Tyler KL. Herpes simplex virus infections of the central nervous system: encephalitis and meningitis, including Mollaret's. Herpes 2004;11 Suppl 2:57A-64A.

3. Malik A, Goyal M, Mishra NK, Gaikwad SB, Padma V. Intracerebral haematoma formation in herpes simplex encephalitis: a case report. Australas Radiol 1997;41:303-5. 
4. Baringer JR. Herpes simplex virus encephalitis. In: Davis LE, Kennedy PG, editors. Infectious Diseases of the Nervous System. Oxford: Butterworth-Heinemann; 2000. p. 139-64.

5. Kennedy PG. Viral encephalitis: causes, differential diagnosis, and management. $J$ Neurol Neurosurg Psychiatry 2004;75 Suppl 1:110-5.

6. Barnett $\mathrm{GH}$, Ropper $\mathrm{AH}$, Romeo J. Intracranial pressure and outcome in adult encephalitis. $J$ Neurosurg 1988;68:585-8.

7. Whitley RJ, Cobbs CG, Alford CA Jr, Soong SJ, Hirsch MS, Connor JD, Corey L, Hanley DF, Levin M, Powell DA. Diseases that mimic herpes simplex encephalitis. Diagnosis, presentation, and outcome. NIAD Collaborative Antiviral Study Group. JAMA 1989;262:234-9.

8. Lai CW, Gragasin ME. Electroencephalography in herpes simplex encephalitis. J Clin Neurophysiol 1988;5:87-103.

9. Marchbank ND, Howlett DC, Sallomi DF, Hughes DV. Magnetic resonance imaging is preferred in diagnosing suspected cerebral infections. Br Med J 2000;320:187-8.

10. Raschilas F, Wolff M, Delatour F, Chaffaut C, De Broucker T, Chevret S, Lebon P, Canton P, Rozenberg F. Outcome of and prognostic factors for herpes simplex encephalitis in adult patients: results of a multicenter study. Clin Infect Dis 2002;35:254-60.

11. DeBiasi RL, Kleinschmidt-DeMasters BK, Weinberg A, Tyler KL. Use of PCR for the diagnosis of herpesvirus infections of the central nervous system. J Clin Virol 2002;25 Suppl 1:S5-11.

12. Griffin DE. Encephalitis, myelitis, and neuritis. In: Mandell GL, Bennett JE, Dolin R, editors. Mandell, Douglas, and Bennett's Principles and Practice of Infectious Diseases. 5th ed. Philadelphia: Churchill Livingstone; 2000. p. 1009-16.

13. Schlesinger Y, Buller RS, Brunstrom JE, Moran CJ, Storch GA. Expanded spectrum of herpes simplex encephalitis in childhood. J Pediatr 1995; 126:234-41.

14. Sener RN. Herpes simplex encephalitis: diffusion MR imaging findings. Comput Med Imaging Graph 2001;25:391-7.

15. Sener RN. Diffusion MRI in Rasmussen's encephalitis, herpes simplex encephalitis, and bacterial meningoencephalitis. Comput Med Imaging Graph 2002;26:327-32.

16. Schroth G, Gawehn J, Thron A, Vallbracht A, Voigt K. Early diagnosis of herpes simplex encephalitis by MRI. Neurology 1987;37:179-83.

17. Sabah M, Mulcahy J, Zeman A. Herpes simplex encephalitis. $\mathrm{Br}$ Med J 2012;344:e3166.
18. Whitley RJ, Soong SJ, Dolin R, Galasso GJ, Ch'ien LT, Alford CA. Adenine arabinoside therapy of biopsy-proved herpes simplex encephalitis. National institute of allergy and infectious diseases collaborative antiviral study. N Engl J Med 1977;297:289-94.

19. Whitley RJ. Herpes simplex encephalitis: adolescents and adults. Antiviral Res 2006;71:141-8.

20. Utley TF, Ogden JA, Gibb A, McGrath N, Anderson NE. The long-term neuropsychological outcome of herpes simplex encephalitis in a series of unselected survivors. Neuropsychiatry Neuropsychol Behav Neurol 1997;10:180-9.

21. Marschitz I, Rodl S, Gruber-Sedlmayr U, Church A, Giovannoni G, Zobel G, Mache CJ, Raith J, Plecko B. Severe chorea with positive anti-basal ganglia antibodies after herpesencephalitis. $J$ Neurol Neurosurg Psychiatry 2007;78:105-7.

22. Yan HJ. Herpes simplex encephalitis: the role of surgical decompression. Surg Neurol 2002;57:20-4.

23. Adamo MA, Deshaies EM. Emergency decompressive craniectomy for fulminating infectious encephalitis. J Neurosurg 2008;108:174-6.

24. Taferner E, Pfausler B, Kofler A, Spiss H, Engelhardt K, Kampfl A, Schmutzhard E. Craniectomy in severe, life-threatening encephalitis: a report on outcome and long-term prognosis of four cases. Intensive Care Med 2001;27:1426-8.

25. Ebel H, Kuchta J, Balogh A, Klug N. Operative treatment of tentorial herniation in herpes encephalitis. Childs Nerv Syst 1999;15:84-6.

26. Lo WB, Wilcock DJ, Carey M, Albanese E. Neurological picture. Herpes encephalitis complicated by cerebral haemorrhage. JNeurol Neurosurg Psychiatry 2013;84:1404-6.

27. Sobel RA, Collins AB, Colvin RB, Bhan AK. The in situ cellular immune response in acute herpes simplex encephalitis. Am J Pathol 1986; $125: 332-8$

28. Esiri MM. Herpes simplex encephalitis. An immunohistological study of the distribution of viral antigen within the brain. $J$ Neurol Sci 1982;54:209-26.

Cite this article as: Abdul Jalal MJ, Fernandez SJ, Varghese P, Menon MK. Decompressive craniectomy in herpes simplex encephalitis. Neuroimmunol Neuroinflammation 2015;2(3):182-6.

Source of Support: Nil. Conflict of Interest: No.

Received: 03-03-2015; Accepted: 15-04-2015 